\title{
Las Reformas Económicas de China y la Geopolítica del Petróleo: un análisis de política exterior a la luz de la cuestión energética ${ }^{1}$
}

\author{
As Reformas Econômicas da China e a \\ Geopolítica do Petróleo: uma análise de política \\ externa à luz da questão energética \\ China's Economic Reforms and the
Geopolitics of Oil: a foreign policy analysis
in the light of the energy issue
}

DOI: $10.21530 /$ ci.v13n3.2018.819

Rafael Shoenmann de Moura ${ }^{2}$

\section{Resumen}

El objetivo de este artículo es, a partir de la evolución de la estructura energética de China, evaluar los distintos delineamientos de su política exterior y las implicaciones geopolíticas de su diplomacia. Después de dilucidar antecedentes históricos, el recorte temporal empleado será enfático a partir de 1993 - cuando el país asiático se convierte en importador neto

1 Este artigo é uma atualização do debate feito originalmente num trabalho final de disciplina que tive na Pós-Graduação em Ciência Política do Iesp-Uerj com os professores Carlos Milani e Maria Regina Soares de Lima, docentes sempre solícitos e incentivadores da submissão do mesmo. E, é claro, um especial agradecimento à professora Isabela Nogueira, grande referência que tenho em estudos sobre a China; e a Alexandre Palhano, querido amigo e professor que inspirou meu interesse original pelo "País do Meio". Felicito também os dois pareceristas que contribuíram para me auxiliar em mitigar imperfeições da versão original desse escrito. No mais, todos os equívocos e imprecisões aqui contidos são de minha inteira responsabilidade.

2 Estudante de PhD em Estudos do Desenvolvimento no Instituto Superior de Economia e Gestão (ISEG) da Universidade de Lisboa. Doutorando pelo Programa de Pós-Graduação em Ciência Política do Instituto de Estudos Sociais e Políticos (IESP-UERJ), onde é Bolsista FAPERJ Nota 10. Pesquisador integrante do Núcleo de Estudos do Empresariado, Instituições e Capitalismo (NEIC) e do INCT/PPED, também é vinculado ao Laboratório de Estudos em Economia Política da China (LabChina-UFRJ) e à Associação Latino-Americana de Ciência Política (ALACIP), onde desempenha as funções de consultor e secretário assistente. Organizou ainda, junto com os professores José Szwako e Paulo D’Avila, o livro “Estado e Sociedade no Brasil: a obra de Renato Boschi e Eli Diniz” (Rio de Janeiro: Ideia D, 2016).

Artigo submetido em 24/06/2018 e aprovado em 22/11/2018. 
de petróleo - hasta años recientes, mostrando los impactos y desdoblamientos de décadas de reformas de apertura, modernización económica y transformaciones productivas. La hipótesis operada en este trabajo es que la sinergia entre la evolución de los lazos bilaterales chinos y su respectiva política para el sector energético (específicamente el petrolero) se encuentra correlacionada en parte al empleo estratégico de su poderío económico para mitigar vulnerabilidades externas a su ascenso. Como objetos de consulta para validación analítica empírica y sustantiva, haré uso de informes de agencias de energía y de las propias firmas petroleras, y también datos secundarios encontrados en el seno de la bibliografía movilizada. La conclusión encontrada es que la expansión económica china en continentes como América Latina, África y Oriente Medio posee un fuerte condicionante directo en su dependencia por recursos naturales, con la energía, en particular, dictando el tono para una diplomacia más asertiva y ampliación de los los vínculos comerciales.

Palabras clave: China; desarrollo económico; petroleo; geopolítica; dependencia energética.

\section{Resumo}

O objetivo deste artigo é, a partir da evolução da estrutura energética da China, avaliar os distintos delineamentos de sua política externa e as implicações geopolíticas de sua diplomacia. Após elucidar os antecedentes históricos, o recorte temporal empregado será enfático a partir de 1993 - quando o país asiático se torna importador líquido de petróleo - até anos recentes, mostrando os impactos e desdobramentos de décadas de reformas de abertura, modernização econômica e transformações produtivas. A hipótese operada neste trabalho é de que a sinergia entre a evolução dos laços bilaterais chineses e sua respectiva política para o setor energético (especificamente o petrolífero) encontra-se correlacionada em parte ao emprego estratégico de seu poderio econômico para mitigar vulnerabilidades externas à sua ascensão. Como objetos de consulta para validação analítica empírica e substantiva, farei uso de relatórios de agências de energia e das próprias firmas petroleiras, e também dados secundários encontrados no bojo da bibliografia mobilizada. A conclusão encontrada é de que a expansão econômica chinesa em continentes como América Latina, África e Oriente Médio possui um forte condicionante direto em sua dependência por recursos naturais, com a energia, em particular, ditando o tom para uma diplomacia mais assertiva e ampliação dos laços comerciais.

Palavras-chave: China; desenvolvimento econômico; petróleo; geopolítica; dependência energética. 


\begin{abstract}
The goal of this article is, departing from the evolution of China's energy structure, to evaluate the different outlines of Chinese foreign policy and the geopolitical implications of its diplomacy. After elucidating historical antecedents, the time frame will be emphatic from 1993 - when the Asian country becomes a net importer of oil - until recent years, showing impacts and ramifications of decades of opening reforms, economic modernization and productive transformations. The hypothesis of this work is that the synergy between the evolution of Chinese bilateral ties and their respective policy for the energy sector (specifically the oil sector) is correlated in part with the strategic use of its economic power to mitigate external vulnerabilities to its rise. As objects of consultation for empirical and substantive analytical validation, I will make use of reports from energy agencies and the oil companies themselves, as well as secondary data found in the bulge of the mobilized bibliography. The conclusion reached is that China's economic expansion in continents such as Latin America, Africa and the Middle East is strongly and direct conditioned by its dependence on natural resources, with energy in particular setting the tone for more assertive diplomacy and broadening commercial ties.
\end{abstract}

Keywords: China; economic development; oil; geopolitics; energy dependency.

\title{
Introducción
}

El presente trabajo investiga las tendencias de la política exterior china en concordancia con la cuestión energética nacional, particularmente de la demanda estructural por petróleo. Tomando el período comprendido entre 1993 - cuando China alcanza la condición de importadora neta de tal commodity - hasta los días actuales, se buscará establecer interfaces entre la dimensión doméstica de la economía política del país y la actuación diplomática practicada por el Partido Comunista de China (PCCh). Esta amalgama entre la esfera endógena y la exógena facilitará trazar como el imperativo de la seguridad energética impactó profundamente en las transformaciones ocurridas, con escrutinio de las relaciones geopolíticas y un mapeamiento de los resultados, riesgos y oportunidades existentes en tal área.

En una definición general simple, la seguridad energética puede entenderse como la garantía de recursos suficientes (donde el petróleo es sólo uno de ellos) para atender requerimientos de las diferentes economías nacionales por las décadas futuras (YERGIN, 2006). Es un componente fundamental de la propia seguridad nacional en términos del funcionamiento exitoso de una economía industrializada 
moderna; con las fuentes básicas podendo estar posiblemente localizadas en áreas de recurrentes turbulencias y conflictos políticos. Es necesaria, justamente por eso, la actuación del Estado; con los gobiernos domésticos asumiendo tal responsabilidad crítica por medios diplomáticos, económicos y militares (KLARE, 2016).

Evidentemente, la cuestión adquiere distintas connotaciones según la estructura productiva de cada nación y momento analizado: para los países desarrollados (por ejemplo, de la Organización para la Cooperación y el Desarrollo Económicos - OCDE), la dicha seguridad se refiere a la disponibilidad de fuentes suficientes a precios "sostenibles". Para los países exportadores intensivos de energía, el énfasis atribuido al concepto alude más al mantenimiento de la demanda para sus ventas externas, garantizando recetas para esos Estados. Por último, para países como India y China, se refiere a la adaptación rápida a la nueva dependencia de los mercados globales que adquirieron con su ascenso en el plano geoeconómico (YERGIN, 2006) ${ }^{3}$.

Por lo tanto, la hipótesis aquí operada trata de la existencia de una posible correlación entre las relaciones comerciales bilaterales y las exclusivas del ámbito energético, algo entendible a la luz de la estrategia china de la utilización de sus herramientas de proyección económica para dilución de riesgos políticos y viabilidad de su presencia y seguridad en el tablero global de recursos naturales.

La próxima sección buscará hacer una reconstitución histórica de los ejes orientadores y paradigmáticos de la política exterior de la República Popular de China (RPC) desde las reformas y apertura al mundo exterior, a partir de la Tercera Sección Plenaria del $11^{\circ}$ Comité Central del PCCh, en 1978, y el gobierno de Deng Xiaoping. En la sección 2 se adentrará específicamente en el análisis sobre la evolución de la estructura energética china a la luz de las transformaciones económicas en boga, discutiéndose sobre las instituciones componentes de las capacidades burocráticas estatales para el sector del petróleo, exponiéndose también la división geográfica y social del trabajo dentro de este marco institucional. En este sentido, las empresas petroleras chinas serán adoptadas analíticamente como instrumentos sinérgicos del Estado para la ejecución tanto de una política comercial para atender a la demanda creciente por la commodity como de la política exterior,

3 Yergin (2011) proporciona un panorama interesante sobre la geopolítica de la energía y posibles desdoblamientos futuros para el inicio del siglo XXI. Ya para una genealogía histórica sintetizando el debate sobre el concepto de seguridad energética y cómo el mismo adquirió distintos matices en las literaturas de los estudios de seguridad, economía política internacional y geopolítica, ver Nunes (2013). 
capilarizando Beijing de influencia en los diversos países y continentes. En la sección 3, a su vez segmentada en dos subsecciones menores (una discutiendo los desdoblamientos sobre la estructura del mercado de petróleo y otra sobre las rutas de transporte del producto al país asiático), se intentará obtener respuestas a cuestionamientos hechos a partir de la ascensión china y su sed energética, con sus respectivas características y desafíos, y qué implicaciones geopolíticas pueden ser abstraídas de las tendencias encontradas. En la cuarta y última sección, por fin, serán traídas las consideraciones generales incautadas a partir de este estudio.

\section{La política exterior china y el imperativo de la estabilidad económica}

Además del notable éxito modernizante de las reformas económicas, los cambios operados por Deng y la segunda generación de líderes del PCCh se extendieron de forma bastante curiosa para el dominio de la política exterior de China, con una interacción intrínseca e continua entre oportunidades y limitaciones, desafíos y amenazas, tanto a nivel doméstico como externo (HEBRON, 2011; LI, 2012).

En el curso de las reformas, los esfuerzos de dos décadas han contribuido para que, a finales de siglo, China tenga una estrategia multilateral desplegada en varios niveles y canales en las relaciones internacionales, desempeñando un papel frecuentemente sinérgico para el mantenimiento y viabilidad de su trayectoria de desarrollo. Con objetivo de adecuarse a un patrón de acumulación de capital y crecimiento donde dependía bastante de las inversiones extranjeras y de la inserción y amalgama junto a las cadenas productivas regionales y mundiales para alcanzar crecimiento y generación de ingresos, el gobierno chino estableció una política exterior coordinada para la construcción económica, denotando la relevancia de un ambiente periférico estable. Esto requirió, en diversos momentos, reevaluaciones de su propia situación internacional, con acompañamiento atento de las tendencias y coaliciones existentes entre los países, así como un pragmatismo rígido en la línea y actitud de sus gobernantes. ${ }^{4}$

4 Zhang denota que la política exterior china representativa de la era Deng está cristalizada básicamente en los ejes determinados por la $4^{\text {a }}$ Sección del $6^{\circ}$ Congreso Nacional del Pueblo (CNP), en marzo de 1986, destacándose entre ellos la oposición al hegemonismo, el mantenimiento de los Cinco Principios de Coexistencia Pacífica, la auto-declaración de su identidad como perteneciente al Tercer Mundo, buscando fortalecer la solidaridad y la cooperación con otros países en desarrollo, la defensa de la Carta de las Naciones Unidas, entre otros (2012). 
El enfoque integracionista con la economía regional y global, encontrando facilitador en la estrategia de crecimiento export-led, requería buenas relaciones junto a otros países, siendo factor de peso para explicar la mayor participación en las instituciones multilaterales mundiales (SHI, 2008; LAI; KANG, 2012; SUTTER, 2012). Tal postura cooperativa pareció ser la alternativa más viable ante las oportunidades de inserción internacional colocadas en la década de los 1990, con la percepción preocupante sobre el unilateralismo estadounidense y su "hegemonía" haciendo con que China buscase coaliciones para obligar a la balanza hacia un multilateralismo un poco más democrático, figurando de forma más prominente en los asuntos periféricos y mundiales (LI, 2012; SUTTER, 2012). Se resalta, sin embargo, que la posición china en el multilateralismo a lo largo de las décadas consiguientes a las reformas de apertura se mostraron relativamente selectivas. $\mathrm{Su}$ grado de compromiso varió según el tema en los más diversos foros e instancias, con claro privilegio para la esfera económica (comercial) sobre otras, como, por ejemplo, de los derechos humanos o cuestiones ambientales (CABESTAN, 2010).

Por su parte, en lo que se refiere a las grandes potencias que históricamente fueron elemento clave para su posicionamiento en la política exterior, China instrumentalizó las tendencias cambiantes de cada momento para hacer efectivos al máximo posible resultados positivos, siempre dotada de una postura de no alineamiento y no-confrontación (ZHANG, 2012).

Por lo tanto, desde las reformas económicas serían perceptibles condicionamientos y complementariedades cada vez mayores entre la estructura interna de China, concatenando todos los eventos de su integración al capitalismo, y las distintas fuerzas y actores globales (SHI, 2008; LI, 2012; LAI; KANG, 2012; SUTTER, 2012; SHAMBAUGH, 2013). Fue también la creciente y ya referida interdependencia económica, adquirida por la integración paulatina del polo manufacturero chino a los flujos de capitales circulantes, que habría dado a sus líderes incentivos para influir en el ambiente externo. Las propias directrices para asegurar condiciones de estabilidad económica emergieron, entonces, como fuerzas motrices de su orientación diplomática, donde incluso las metas de seguridad nacional estarían condicionadas por motivos de naturaleza fundamentalmente económica y programadas para forjar un "ambiente internacional pacífico" que endosaría o, por lo menos, no pondría trabas al desarrollo (LAI; KANG, 2012).

Por la forma en que los líderes en Beijing operan las variables para lograr intereses nacionales, considerando las limitaciones impuestas por los recursos endógenos y el contexto internacional donde están insertados, es que se puede 
evaluar el significado del ascenso de China en el campo externo. Después de los intentos ad hoc de abordar los desafíos de la insatisfacción de parte de la comunidad internacional (Occidente) con las respuestas autoritarias a las manifestaciones de 1989, en Tiananmen, y el desmantelamiento de los regímenes comunistas del Este Europeo, su política exterior adentró en un "ciclo" aparente de acciones más sistemáticas y consensuadas, principalmente a partir de 1996 y 1997, dentro de un conjunto coherente denominado por Avery Goldstein (2001) como "gran estrategia". 5 De ese modo, se dibujaban contornos de una línea diplomática que reflejaba una respuesta pragmática a las circunstancias del país y también a las lecciones sacadas por sus líderes de las tendencias turbulentas del inmediato post-Guerra Fría (GOLDSTEIN, 2001).

En la línea de los puntos dilucidados hasta aquí, además del PCCh abordar preocupaciones inmediatas con su propia supervivencia política, la estrategia de la pragmática política exterior de China buscó plantear una difícil ingeniería para el desarrollo económico doméstico necesario para potenciar sus capacidades. Se puede decir, de cierta forma, que los elementos de esta orientación estaban presentes desde la era Deng, con la búsqueda de una política exterior independiente que permitiría lograr ventajas en un ambiente internacional supuestamente menos amenazador, con la bipolaridad dando lugar a la multipolaridad y a la oportunidad pacífica de desarrollo.

Finalmente, se atenta al punto con relación a la diplomacia económica china, pertinente al hecho de que su absorción en el orden capitalista global generó una necesidad expansiva de enfocar su política exterior en la búsqueda de ofertas seguras de energía, con pressiones engatilladas por el ritmo fervoroso del crecimiento industrial observado en el país asiático al largo de las últimas décadas. En la estela de esta demanda, posiblemente, estará el riesgo de mayores tensiones con los vecinos en escenarios futuros (LAI; KANG, 2012). Las disputas en torno a la cuestión de la energía, por lo tanto, adquieren cada vez más relevancia en las consideraciones políticas conforme la dependencia se intensifica, exigiendo comportamientos más asertivos por parte de Beijing que pueden fomentar eventuales desentendimientos o respuestas hostiles de las demás naciones del globo o del proprio sudeste asiático.

5 La coherencia de tal enfoque sólo fue victoriosa, según el autor, en función del centralismo decisorio del régimen político chino, facilitando al núcleo del PCCh incrustado en el Estado proveer una dirección amplia dentro de la cual los actores económicos deberían guiarse (GOLDSTEIN, 2001). 


\section{La trayectoria de desarrollo de China: implicaciones para el sector energético y su estructuración}

En perspectiva global, China surge como la mayor nación consumidora energética desde 2011, quedando atrás sólo de EEUU en lo que se refiere al consumo específico de petróleo (U.S. ENERGY INFORMATION ADMINISTRATION, 2015). ${ }^{6}$ En esta relación, la participación del carbón todavía desempeña el mayor peso en su matriz (alrededor de dos tercios o $65 \%$ ), siendo uno de los pocos recursos minerales detenidos en gran abundancia por el país asiático, a pesar de la problemática logística de las minas de carbón se concentraren en las provincias de las regiones Norte y Nordeste (NAUGHTON, 2007; WU; STOREY, 2008; GARRISON, 2011; PALHANO, 2012; CURRIER, 2012). Los diferenciales positivos del carbón serían sus bajos costos y gran cantidad - hay que subrayar que, además de las sensibles problemáticas ambientales generadas, este sector contiene altos índices de precariedad en las condiciones laborales. Sin embargo, ante el enorme tamaño de tales reservas, sumadas al costeo irrisorio, sigue siendo elemento basilar de la estructura productiva china, por la propia óptica de la economía (CURRIER, 2012).

Con respeto al crecimiento económico e industrial masivo post-reformas, incrementando la demanda por bienes de consumo duraderos, se consolidó una sede energética sin escalas, afectando directamente a los mercados de esas materias primas y sus derivados, contribuyendo a acelerar y retroalimentar aún más la integración comercial china junto al resto del mundo. En 1993, China ya figuraba como importadora neta de petróleo, con su demanda por el producto prácticamente doblando por los diez años siguientes y la importación con el tiempo superando la mitad de su consumo total (YERGIN, 2006). ${ }^{7}$ El grado de dependencia creciente de las importaciones alzó la seguridad energética como una de las mayores preocupaciones destacadas en las consideraciones estratégicas del PCCh y los planes quinquenales del Partido-Estado chino, con exigencias en tal área condicionando directamente sus capacidades de maniobra diplomática según cada caso (WU; STOREY, 2008). Esta sección, por lo tanto, mapeará el camino evolutivo de la estructura nacional china de energía, tensada por el consumo per

6 En 2012, China figuraba como la segunda mayor consumidora mundial de petróleo, a pesar de contar con sólo el $20 \%$ de su consumo total primario (U.S. ENERGY INFORMATION ADMINISTRATION, 2015).

7 Entre 1978 y 2005, por ejemplo, la producción total de energía creció a tasas medias del 4,5\% a.a., mientras que el consumo, en la estela dinamizadora de las reformas, creció el 5,2\% a.a. En 1993, ya no era posible para China coadunar la demanda interna únicamente con la producción doméstica (NAUGHTON, 2007). 
cápita de petróleo excediendo por márgenes cada vez mayores la producción per cápita relativamente estancada, atestada por el Gráfico 1 abajo:

\section{Gráfico 1. Evolución Histórica del Consumo y Producción per cápita (Kg) de Petróleo en China, 1990-2016}

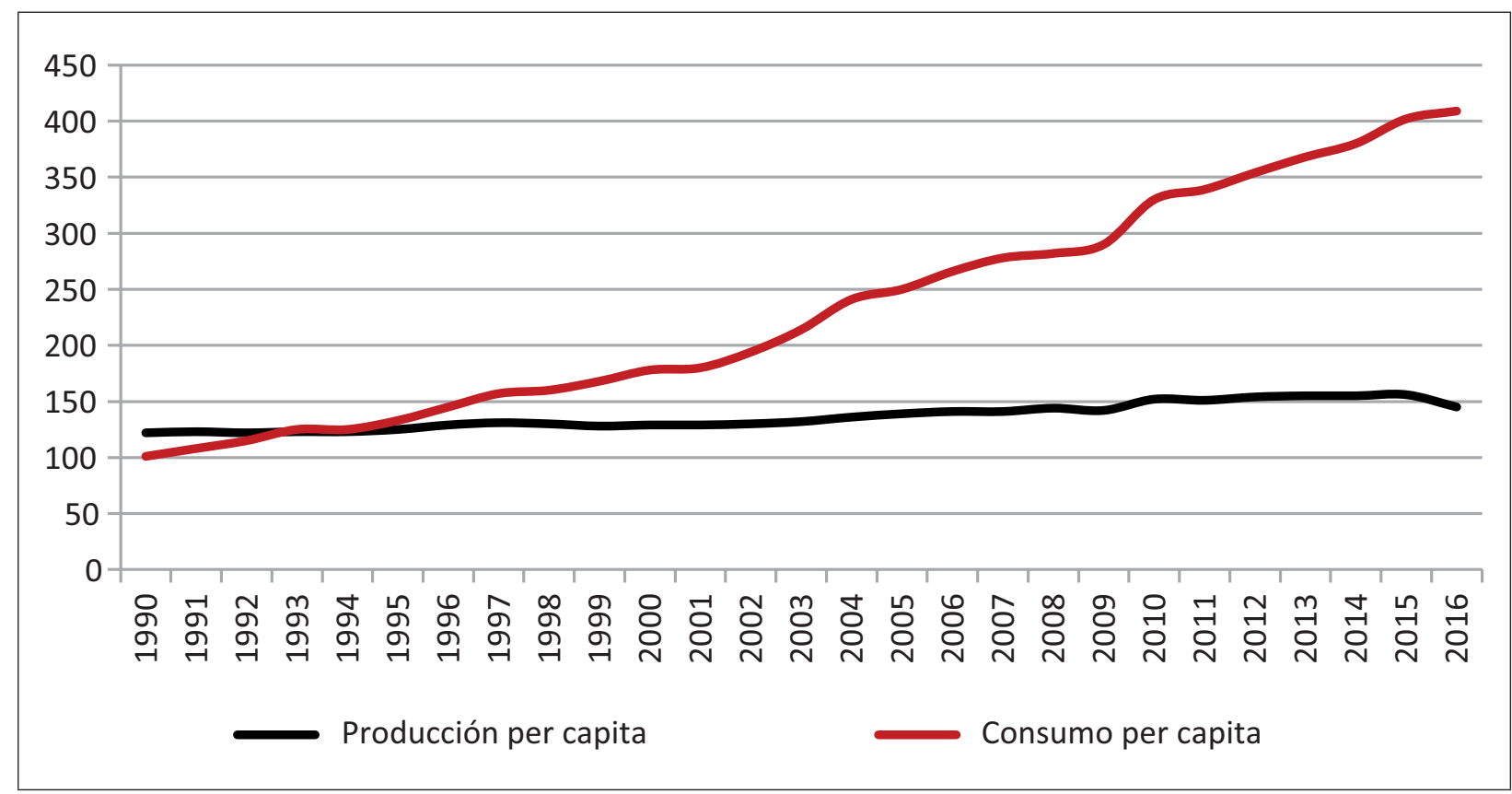

Fuente: Elaboración propia a partir de NATIONAL BUREAU OF STATISTICS, 2017.

Este apetito creciente de China, ahora convertida en el mayor polo manufacturero global mientras que las economías de la OCDE pasaban por reestructuraciones productivas y se volvían cada vez más ancladas en el sector de servicios, engendró nuevas consideraciones para los propios caminos futuros de la geopolítica global. ${ }^{8}$ El gigantismo energético chino puede ser atestiguado por el propio aumento de su participación en el consumo mundial (por millones de toneladas), como muestran los Gráficos 2 y 3 abajo.

8 A partir de finales de la década de 1970, en medio de los procesos de liberalización financiera, integración productiva y apertura comercial que los países desarrollados pasaban, con advenimiento de la desregulación neoliberal y erosión de los "años dorados" del capitalismo del Post-Guerra, hubo un desplazamiento de la base manufacturera de Occidente hacia el Este Asiático. China, en este sentido, fue una de las últimas beneficiarias de esta transformación; que posteriormente se intensificara por el influjo de capitales procedentes de Japón tras el Acuerdo de Plaza en 1985 (PINTO, 2011). 


\section{Gráfico 2. Evolución de las Parcelas Regionales (\%) del Consumo} Total de Energía, 1973-2015

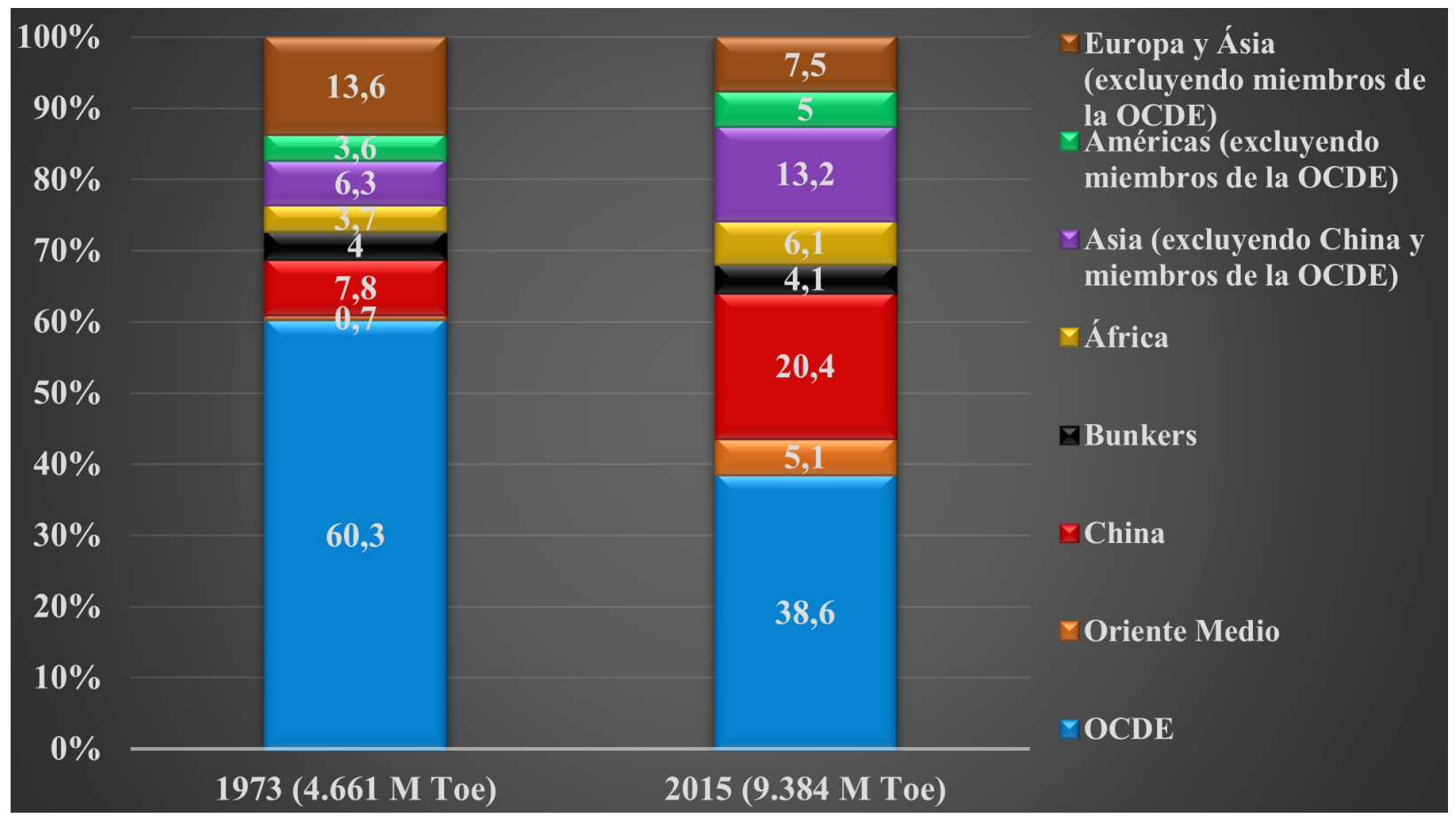

Fuente: INTERNATIONAL ENERGY AGENCY, 2017.

Gráfico 3. Evolución de la Demanda por Petróleo de las Cinco Mayores Naciones Consumidoras (miles de barriles al día), 1996-2015

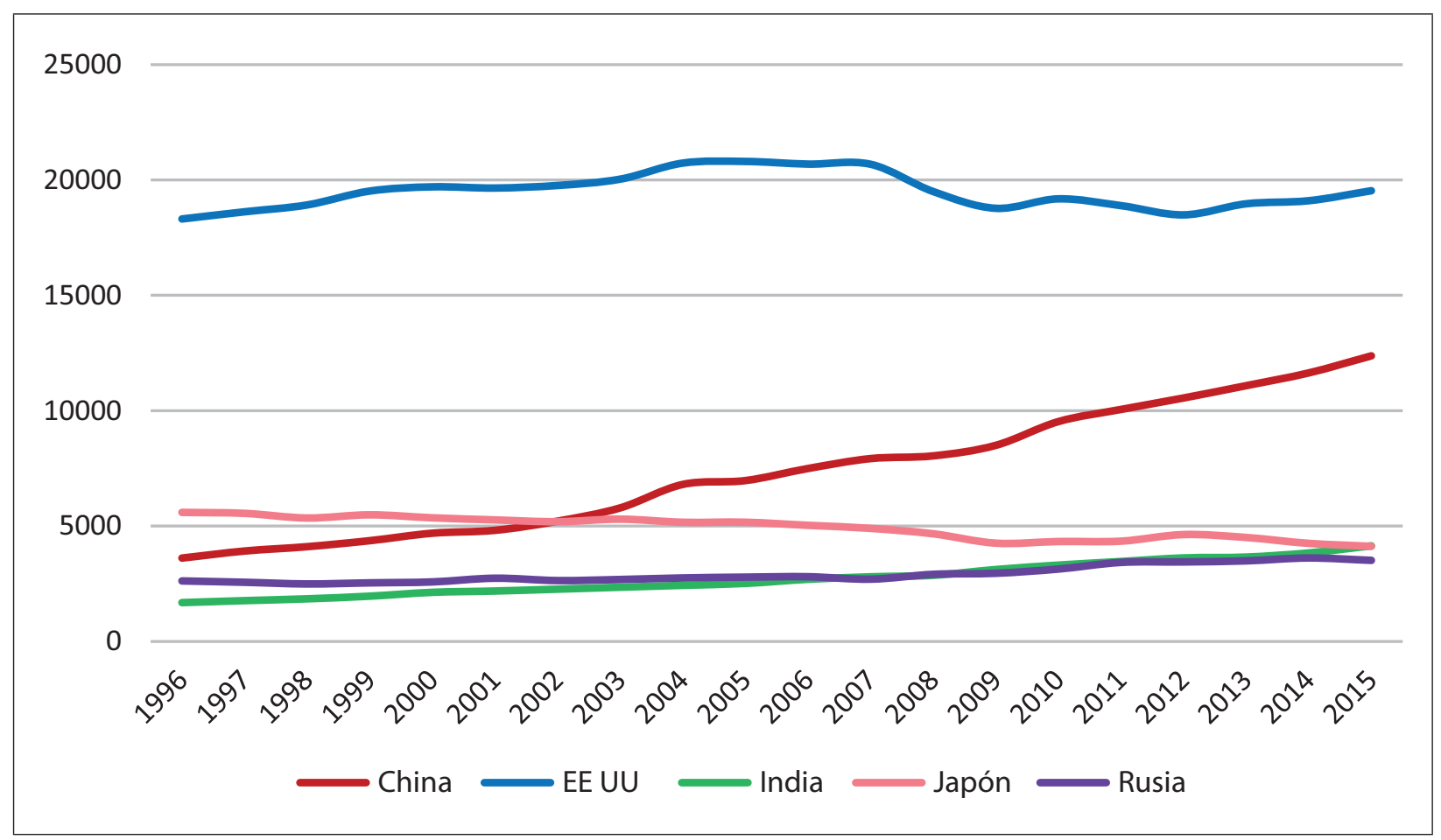

Fuente: U.S. ENERGY INFORMATION ADMINISTRATION, 2017. 
A pesar de los esfuerzos gubernamentales para un mayor aprovechamiento de sus reservas domésticas, el país se ve cada vez más dependiente de las fuentes externas de oferta energética, excepto en el caso de energía eléctrica donde logra atender la demanda interna con sus proprias fuentes hidráulicas y de carbón (NATIONAL BUREAU OF STATISTICS, 2017). En vista de ello, el crecimiento dramático de la demanda de petróleo se presenta como justificación política para la expansión internacional de sus firmas en tal sector - sus National Oil Companies o NOC (SHAMBAUGH, 2013). Dotada de la mayor población mundial con casi mil millones y cuatrocientos millones de habitantes, la eventual incapacidad del país de satisfacer su necesidad interna preocupa tanto a los liderazgos del régimen dominante del PCCh como para otros países y actores que pueden quizás ver en su emergencia una posible amenaza a las sus propias disponibilidades de tales recursos en un horizonte de mediano y largo plazo (CURRIER, 2012; TAYLOR, 2014). Antes de evaluar la validez de tales interpretaciones y temores, lo que se hará en la próxima parte del trabajo es trazar las facetas institucionales del sector petrolero chino, su constitución y delineamiento a la luz de una cronología de las reformas económicas.

En lo que se refiere a esta temática, el marco fundamental e histórico de China fue el descubrimiento de los campos de Daqing, en 1959, y Shengli, en 1961, importantes por hacer la nación pasar incólume por los adversos choques del petróleo de la década de 1970, siendo capaz de continuar atendiendo a la demanda interna, en aquel período aún no tan significativa. Esto sin hablar de su arregimiento como factor movilizador del orgullo nacional y de fuerza política por parte de Mao Zedong, principalmente en el período seguido de la racha sinosoviética (KAMBARA; HOWE, 2007; ANDREWS-SPEED, 2010; TAYLOR, 2014). ${ }^{9}$

Con respecto a la estructura burocrática del sector energético, la división interna en ella existente en este período comprendía dos grandes ramificaciones gubernamentales: el Ministerio de Geología (MG) y el Ministerio de la Industria de Petróleo (MIP). El primero se encargaba de la explotación, mientras el segundo quedaba a cargo de la producción, el refino y el flujo. Pero, a lo largo de la década de 1960, hubo una fuerte delegación de poderes institucionales al MIP, con los gobernantes y burócratas chinos ya considerando y calculando políticamente la

9 Se destaca que, en los primeros años de la República Popular, antes del fallecimiento de Stalin y de la ruptura entre los dos países, la URSS tuvo suma importancia en el auxilio a la formatación y desarrollo del sector mineral y energético chino, con envío de técnicos para planificación de plantas y unidades de explotación (ANDREWS-SPEED, 2010). 
importancia de la centralidad administrativa en el escenario post-desprendimiento de la URSS (KAMBARA; HOWE, 2007; PALHANO, 2012). ${ }^{10}$ De este modo, fue notorio cómo tal estructura productiva logró atravesar, relativamente blindada, a episodios más agudos de contestación social del período maoísta, como la Revolución Cultural o la propia lucha política entre facciones en el seno del Estado y del PCCh, con la disputa entre la "Gangue de los Cuatro" y el ala reformista liderada por Deng y Hua Guofeng.

Otros cambios significativos sólo serían operados con el ascenso de Deng, contando con la importante ayuda de su economista jefe Chen Yun y una reorientación de la economía en favor de la industria ligera, productora de bienes de consumo, más intensiva en trabajo y menos en energía. Esto requirió subsiguientes reorganizaciones institucionales y cambios en el marco de gobernanza que acabaron debilitando la influencia de la industria del petróleo junto a la alta cúpula del Estado chino, una vez que las inversiones en la industria pesada a lo largo de las tres décadas anteriores ya se habían madurado, haciendo que tal sector perdiera la prioridad que antes tenía en la economía política de planificación central maoísta (KAMBARA; HOWE, 2007; PALHANO, 2012).

En el marco de las reestructuraciones económicas realizadas por el gobierno en la década de 1980, reformularon las firmas estatales para engendrar una división sectorial del trabajo en el cuerpo de las NOC, con la SINOPEC (China Petroleum and Chemical Corporation) asentada en las actividades downstream mientras que la CNPC (China National Petroleum Company) y la CNOOC (China National Offshore Oil Company) asumían responsabilidades upstream en operaciones en la tierra y en el mar respectivamente. ${ }^{11}$

Si antes de la década de 1990 las firmas petroleras estatales chinas actuaban de modo desagregado y segmentado, enfrentando a la falta de competitividad e interacción en una cadena productiva amplia, en 1998 se pone en marcha una reformulación de la organización industrial para integrar verticalmente las actividades de las NOC y permitir una dinámica de mayor competitividad entre las mismas dentro de la meta del Partido-Estado de alzarlas como compañías

10 Por gobernantes me refiero específicamente a Mao Zedong, Zhou Enlai y Yo Qiuli (ministro del MIP), repensando la estrategia de desarrollo a la luz del llamado “Tercer Front”, política de autoconfianza y centralismo en respuesta al momentáneo aislamiento chino de las dos superpotencias.

11 Las terminologías upstream y downstream se refieren a diferenciaciones dentro de la cadena productiva de petróleo, donde la primera tangencia los procesos de perforación, explotación y tratamiento del producto, mientras que la segunda se refiere al transporte, distribución y comercialización. 
globales (ANDREWS-SPEED; DANNREUTHER, 2011; PALHANO, 2012; NOLAN, 2013). ${ }^{12}$ El Cuadro 1 auxilia en el entendimiento de ese esfuerzo integrador con el objetivo de imprimir mayor coordinación a dichas firmas:

\section{Cuadro 1. Reestructuración de las Esferas de Actuación en el Segmento Industrial Petrolífero}

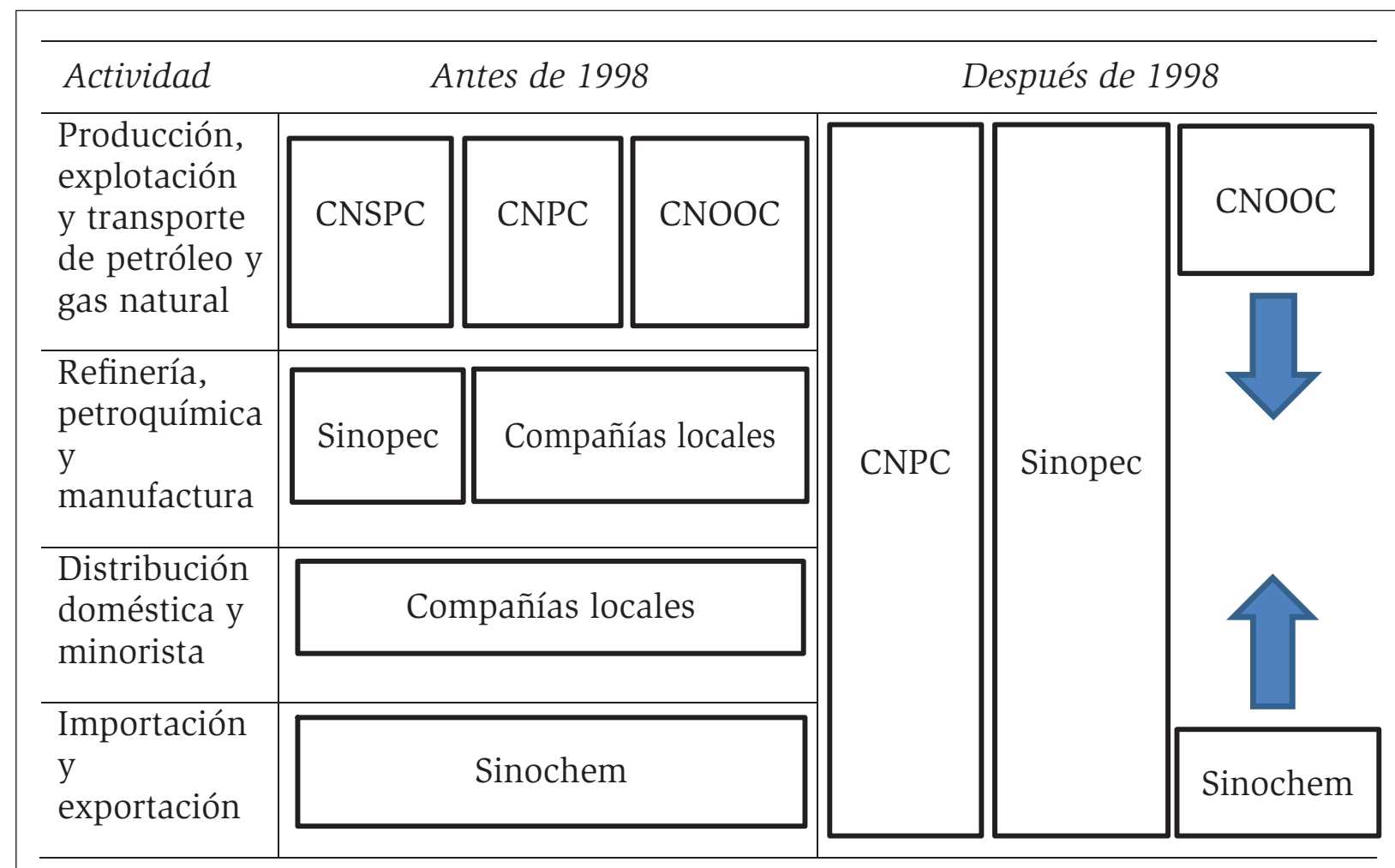

Fuente: PALHANO, 2012.

Esta reestructuración debe ser contextualizada a la luz de la aplicación del $9^{\circ}$ Plan Quinquenal (1996-2000) y su política de los “Campeones Nacionales”, bajo el lema "Grasp the large and release the small" "Sostenga las grandes y suelte las pequeñas”). Tal política industrial, emergente de un proceso de experimentación y combinación de directrices gubernamentales centrales con iniciativas de instancias inferiores, consistió en la selección de 120 grupos empresariales en sectores históricamente caracterizados por fuertes economías de escala. Estos grupos pasarían a gozar de privilegios dentro del planeamiento de las autoridades chinas, que, a pesar de la trayectoria liberalizadora de la economía, le aplicaban fuerte dosis de proteccionismo, principalmente arancelaria (NOLAN, 2001).

12 Nolan (2001) destaca aún la división geográfica de la reestructuración de 1998, con Sinopec quedando a cargo de los activos localizados más en la parte Sur y Este del país, mientras que la CNPC operaba los de las partes Norte y Oeste. 
Así, fue engendrado un cambio importante en la propia naturaleza del control estatal sobre los grandes conglomerados de sectores estratégicos, con el objetivo de una mayor coordinación y regulación del sector público en mercados importantes, como de telecomunicaciones, petroquímica, aeroespacial, minería, construcción civil e infraestructura, etc. La elección por tal política provenía de estudios inclinados sobre las experiencias desarrollistas exitosas de la industrialización retardataria en los países vecinos del Este Asiático (principalmente Corea del Sur) y de la observación de las condiciones existentes en el capitalismo oligopolista avanzado, así como una cuestión del propio orgullo nacional (NOLAN, 2013). Una de las consecuencias no pretendidas de tal política de reestructuración industrial fue la de que las estatales restantes (sin pasar por privatizaciones o cambios en el régimen de propiedad y organizativo) aumentaron su autonomía gerencial y margen de poder político para defender sus "propios" intereses, incluso por veces obstaculizando medidas reformistas defendidas por las autoridades chinas centrales (TAYLOR, 2014).

Taylor (2014), todavía, deteniéndose en la estructura burocrática estatal, argumenta que el poder institucional del gobierno central sobre el sistema bancario y la fijación de precios del petróleo, así como la propiedad de las NOC, aún ha dotado al PCCh de poder significativo en la determinación de las políticas para tal sector. Así, fue capaz de promover también otros objetivos de orden económico (como el control inflacionario), estratégico (fortalecimiento de diferentes sectores industriales según el momento, principalmente los más sensibles a los costos de combustibles) y social (empleabilidad). La centralización se muestra, por lo tanto, imprescindible para la comprensión del proceso decisorio en China, actuando mediante una serie de instrumentos e instituciones de control. ${ }^{13}$ En función de esto, es posible pensar en términos de un "autoritarismo burocrático" más fidedigno para análisis concretos de tal sector (del petróleo), precisamente por centrarse en el papel desempeñado por las elites en el cambio institucional y en el policymaking orientado arriba-abajo, enfatizando la negociación interna del sistema de gobernanza en un Estado altamente jerarquizado (TAYLOR, 2014).

13 Se trata principalmente de: la NDRC (National Development and Reform Commission), responsable por la definición de la estrategia nacional de desarrollo energético y coordinación de los ministerios relacionados con el dicho tema; la SASAC (State-Asset Supervision and Administration Comission), con supervisión y control, principalmente de los campeones nacionales; la posición mayoritaria del Estado como accionista en las estatales de capital abierto; el COD (Central Organization Department); el sistema de nomenklatura (utilizado para nombramientos en los altos cargos de las estatales, generalmente vinculadas a performances y objetivos trazados); y finalmente el propio papel de los bancos públicos (marcadamente el Banco de Desarrollo de China - CDB) en los aportes a las firmas, como se aclarará más adelante en este documento. 
En la interpretación de algunos autores, no obstante, no se podría asumir las NOC solamente como meros apéndices del Estado chino, ya que éstos han hecho, y hacen uso, en diversos casos, de su poder económico y capilaridad política, a remolque de la propia importancia estratégica adquirida en la economía, para influir en decisiones gubernamentales a fin de gozar de beneficios o relativa autonomía decisoria en sus operaciones (ANDREWS-SPEED; MA, 2006; CHEN, 2009; DOWNS, 2010; PALHANO, 2012; TAYLOR, 2014). Un punto pertinente a destacar es que la disputa por la circunscripción del poder decisorio y definición de políticas por parte de las autoridades corporativas de las NOC y líderes gobernantes del Estado chino acaba por reflejar también disputas políticas en el seno del propio PCCh, con la actuación de algunos ejecutivos del petróleo en el país representando fuente de patronaje político y desafío al propio presidente en ejercicio Xi Jinping (TAYLOR, 2014)..$^{14}$

La próxima sección, segmentada en dos partes, por lo tanto, se dedicará primero a analizar el modus operandi de la inserción externa de las NOC y sus consecuencias, además de debatir questiones en lo que se refiere al futuro del mercado mundial de petróleo. A continuación, se evaluaran las consecuencias geopolíticas a partir de las rutas de transporte del dicho producto a China, señalando puntos procedentes o no en los escenarios trazados por la bibliografía utilizada.

\section{China y la geopolítica del petróleo: consideraciones y pronósticos}

En esta sección, primero, serán asignadas las consecuencias estructurales detrás de la lógica de inserción de las NOC chinas en el mercado mundial del petróleo, teniendo como puntos de partida el examen de cuatro cuestionamientos planteados por la autora Erica Downs (2010): cuál el peso de la seguridad energética como determinante eventual para sus inversiones externas (de RPC); el exacto peso de las NOC sobre el sector upstream global; la influencia de la explotación de las estatales chinas en lo que se refiere a la disponibilidad del producto; y la cuestión de cuál es el real impacto del endoso del Estado chino a tales firmas en la

14 Coincidentemente, después de la campaña anticorrupción anunciada por el presidente en 2013, dos relevantes personalidades presas fueron los ex dirigentes de la CNPC Zhou Yongkang y Jiang Jiemin; cuya vinculación con el ex líder Bo Xilai - también preso - levantó sospechas en parte de los medios de comunicacción occidentales sobre expulgos políticos (REUTERS, 2014; BBC; 2015). 
competición con las IOC (International Oil Companies). Ya en la segunda parte lugar de esta sección, se discutirán las limitaciones políticas y económicas impuestas por las problemáticas geográficas y logísticas de transporte, más enfáticamente por el llamado "dilema de Malaca", que desde el punto de vista estratégico representa una preocupación relevante para las autoridades gubernamentales chinas.

\section{a) La inserción externa de las NOC y sus impactos de mercado}

Antes de empezar, algunas consideraciones previas son necesarias sobre la inserción externa china en general: en la búsqueda por recursos, China presentó una postura contradictoria con respecto a la adopción de una línea de acción única y coordinada. La escalada de las necesidades de la RPC reforzó la ya existente inclinación de Beijing de evitar conflictos con Washington y creó posibilidades de convergencia de intereses entre ambas partes, como el mantenimiento de la estabilidad en regiones esenciales en lo que se refiere a la exportación de recursos, como Oriente Medio y el Sudeste Asiático. Al mismo tiempo, China manifiesta apoyo a regímenes de los vulgos "Estados parias", repudiados por la política y retórica estadounidense (por ejemplo, Irán y Corea del Norte), justificándose por su política desprovista de condicionalidades en lo que se refiere al sistema político y las estructuras de gobernanza, tenidos como elementos pertinentes exclusivamente a los actores domésticos de esos países (KAPLAN, 2010). Esta aparente "contradicción", sumada a la activa diplomacia de recursos energéticos de la potencia asiática, contribuyó a sospechas de corto plazo por parte no sólo de Estados Unidos, sino de diversas naciones occidentales. Por una óptica positiva, sin embargo, esto engendró una ventana de opciones y oportunidades para Beijing poner en práctica su estrategia de avance incremental visando una preponderancia regional y global expandida (FRIEDBERG, 2006).

La lógica de internacionalización de las NOC chinas se mostró diversa y ramificada en etapas, englobando procesos productivos de diferentes naturalezas y respondiendo claramente a los desafíos políticos y coyunturales planteados. En la visión de Andrews-Speed y Ma (2006), la internacionalización de las NOC podría segmentarse en tres fases: la primera, comprendida entre 1992 y 1997, asistió a una inserción conducida solamente por la CNPC, con el objetivo de ganar familiaridad con el ambiente de operaciones y negocios globales, adquiriendo prácticas y conocimientos corporativos (por veces a través de joint ventures). En la segunda, que duró de 1997 a 2002, ya sería perceptible un cambio en el 
comportamiento estratégico, con la CNPC pasando por la primera vez a invertir en el desarrollo de proyectos de alto riesgo y manejo de grandes sumas de petróleo, con la compra de activos de explotación cada vez más sustantivos y prioridades geográficas más explícitas. Finalmente, en la tercera fase, desde 2002 hasta hoy, hubo una proyección externa mayor también de CNOOC y la ampliación del alcance geográfico de las estatales petroleras para incluir otras naciones. En estas obras, el apoyo gubernamental permaneció considerable, con el uso de la diplomacia para garantizar la concreción de los negócios en el ramo.

Esta última fase de la internacionalización de las NOC chinas, iniciada pocos meses después del ingreso del país en la Organización Mundial del Comercio (OMC), a finales de 2001, es contextualizada dentro de la lógica más grande de la política "Going Out” (o "Going Global”) del gobierno de la RPC, lanzada en 2002, por Hu Jintao y Wen Jiabao, con el propósito de proyectar con aún mayor asertividad a las firmas chinas (especialmente estatales) en la búsqueda por mayor participación en los mercados y activos externos globales (FRIEDBERG, 2006, p.22). ${ }^{15}$ A pesar de no justificarse únicamente por tal ingreso y por tal política, la fase de internacionalización encontró elementos propulsores en ambos, tras la maduración de la ya citada reestructuración burocrática y ministerial (MEIDAN, 2016).

Con el fuerte aumento del precio del petróleo a partir del mismo año (2002), la diversificación ganó cada vez más relevancia conforme otras NOC, además de la CNPC, iniciaban búsquedas por activos fuera del país. Con respecto al ámbito geográfico, la expansión siguió una lógica objetivando incluir un gran número de países de África y América Latina, así como del propio Sudeste Asiático. Además de eso, la escala y la naturaleza de los proyectos pasaron a cubrir una gama más amplia de actividades petroleras, con las empresas pasando de inversiones de bajo riesgo y proyectos convencionales para actividades que estaban menos familiarizadas. Por último, se señala la tendencia creciente de las firmas chinas a comprar activos de actores ya existentes, negociando de forma directa con las empresas petroleras y los gobiernos respectivos (FRIEDBERG, 2006).

El objetivo principal, tanto de las firmas petroleras cuanto del PCCh, de forma general, sería la adquisición de activos de petróleo de una variedad amplia de oferentes en todo el mundo; y, principalmente a partir de finales de la década de 1990, el gobierno chino actuó íntimamente con las NOC con el objetivo de

15 Para una evaluación bastante resumida del propio gobierno chino acerca de los éxitos y límites encontrados por tal política, ver People’s Republic of China (2017). 
ganar participación en proyectos de importancia estratégica en este sentido. Justamente por ello, en la política exterior, integración a las instituciones y acuerdos multilaterales fue la opción más constructiva seguida (ANDREWS-SPEED; MA, 2006). El papel de estas NOC está en consonancia con el deseado por la burocracia, y sus objetivos son, primordialmente, lograr mayor competitividad vis-à-vis a las empresas occidentales y asegurar energía suficiente internamente, actuando de forma intensa en la adquisición de unidades de producción en el globo. Sin embargo, comparadas a las gigantes de Occidente, las NOC todavía aún tienen un camino por recorrer en términos de competición, internacionalización (ya que buena parte de sus negocios se ubica y vuelve a la propia China) y catching-up tecnológico (DOWNS, 2010).

Pasando ahora a las problemáticas estilizadas del inicio de la sección, en lo que se refiere al primer punto del peso de la seguridad energética como variable explicativa para la determinación de sus inversiones externas, se da que, de hecho, las NOC gozan de mandato gubernamental. No obstante, retratar sus inversiones como mero proyecto unidireccional concebido dentro de la alta casta del gobierno o PCCh en Beijing oscurece una lectura apropiada y objetiva de la lógica e incentivos de mercado, también operando en este juego y guiando la expansión económica de las petroleras chinas (TAYLOR, 2014).

La diversificación de activos, conveniente a los policymakers gubernamentales en función de la rigidez del mercado de tal commodity, no se disocia de las prácticas comunes de los otros grandes actores en esas actividades, mucho menos de elementos estructurales: como las demás firmas de petróleo, tienen necesidad constante de adquirir nuevas reservas para sustituir las agotadas. Sin embargo, lo harían con oportunidades muy limitadas, con las reservas chinas respondiendo sólo al 1,5\% de las reservas petroleras descubiertas y el 2,9\% de las reservas de gas natural mundiales. Como resultado, los activos extranjeros inexorablemente pasan a configurar fuentes importantísimas para el crecimiento en reservas y producción (BRITISH PETROLEUM, 2017; INTERNATIONAL ENERGY AGENCY, 2017). Por último, una preocupación pertinente es que las NOC difícilmente logren producir petróleo suficiente para cubrir todos los requisitos de importación de China, por el simple hecho de que más de tres cuartas partes de las reservas mundiales se encuentren en países que no permiten ninguna participación de capitales extranjeros (DOWNS, 2010).

Pasando al peso de las NOC chinas en las actividades upstream, a pesar de la más reciente preponderancia asumida por la CNPC a través de su subsidiaria 
PetroChina, el real peso de la inserción de las compañías estatales del país en el terreno competitivo de las industrias de petróleo global debe ser relativizado por dos factores: primero, al analizarnos su producción bruta diaria, sólo PetroChina/ CNPC haría frente a las principales IOC, con la CNOOC figurando muy atrás (Gráfico 4). Aunque permanecen invirtiendo en proyectos upstream en decenas de países, sus activos no siempre logran aumentar sustancialmente la producción agregada, aunque se han valorado bastante a lo largo de la última década y media, como atestigua el Gráfico 5. En segundo lugar, no siempre compiten de forma directa con las firmas extranjeras, pues su propia forma de adquisición tiene naturaleza distinta, visando la acumulación de activos específicos esparcidos por el globo en lugar de la lógica centrada en la rentabilidad a corto plazo que impregna las IOC (TAYLOR, 2014).

\section{Gráfico 4. Producción Líquida Diaria Internacional de Petróleo y Gas Natural por Cías Seleccionadas (millones de BOE/día) ${ }^{16}, 2017$}

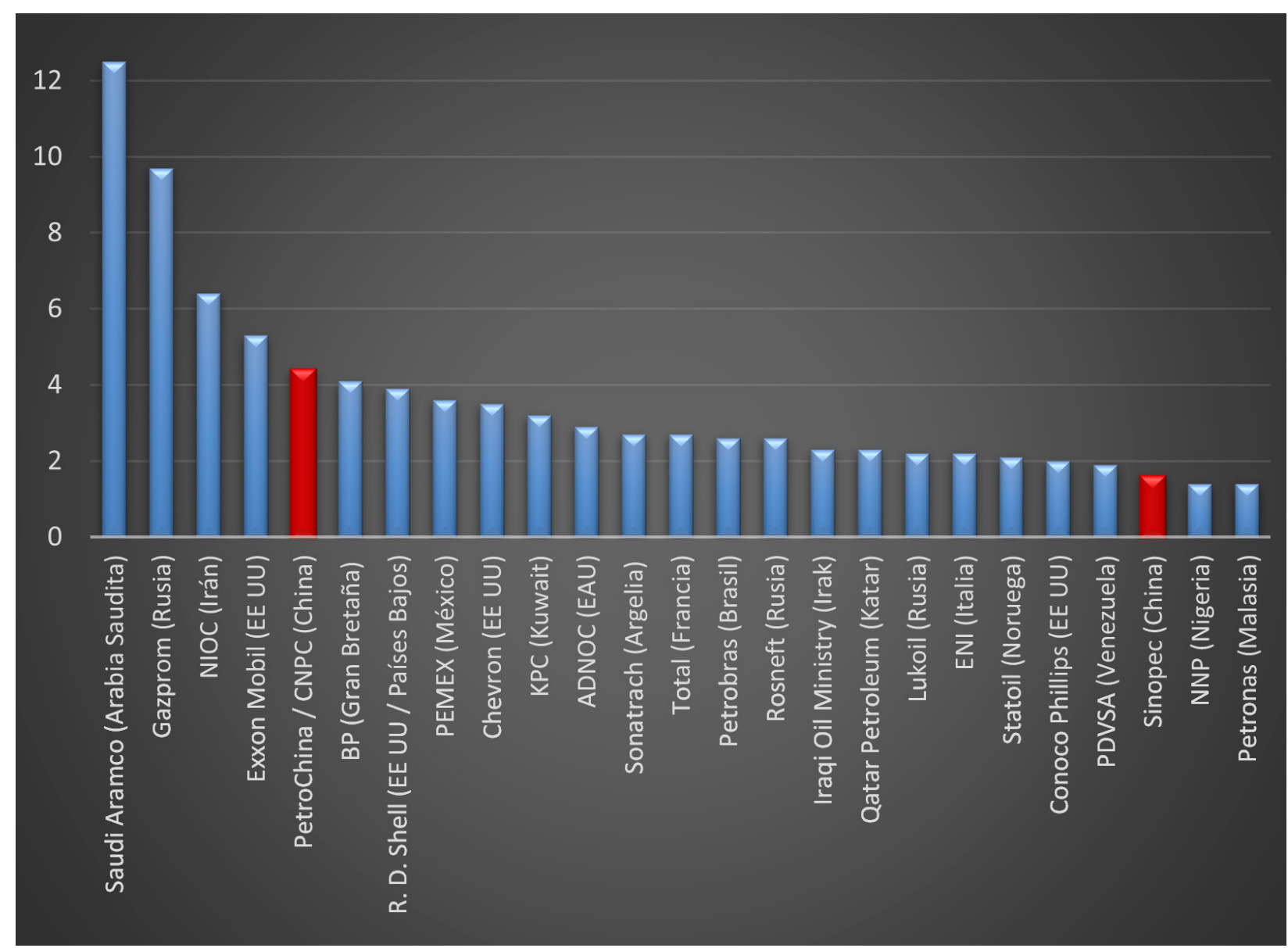

Fuente: FORBES, 2017a.

16 BOE (Barrel of Oil Equivalent) es la sigla regularmente utilizada por diversas autoridades y estudiosos en referencia al patrón de medición del equivalente de energía contenido en un barril de crudo o gas natural. 


\section{Gráfico 5. Las principales compañías de petróleo por valor financiero de sus activos (miles de millones de dólares) ${ }^{17}, 2017$}

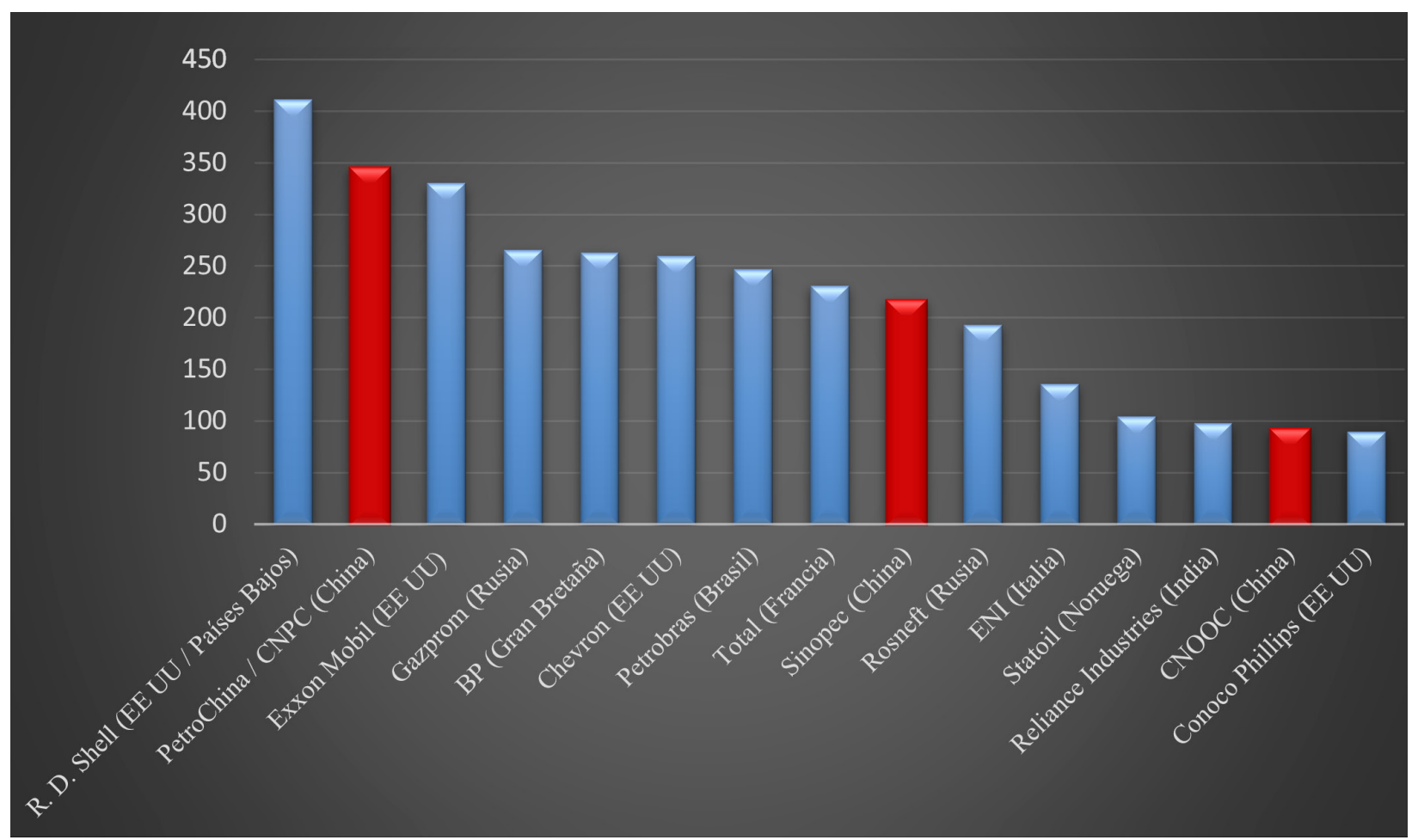

Fuente: FORBES, 2017b.

Sobre el tercer punto de Downs (2010), tratando de la real contribución de la asertividad de las NOC a la adquisición y restricción del monto total de petróleo disponible en el mercado mundial, es posible ver que, en realidad, éstas expanden la oferta existente conforme adentran en campos y emprendimientos poco rentables o atractivos (por los costos elevados). Además, otros factores económicos conectados a la propia proximidad geográfica ayudan a explicar la distribución espacial de las remesas de petróleo de las NOC en otros lugares para la propia China, con $45 \%$ de las importaciones del producto, por ejemplo, proviniendo solamente de Oriente Medio, con 23\% del total de sus activos ubicados en Kazajstán (JIANG; SINTON, 2011). Con el desarrollo de la iniciativa de integración lanzada en 2013, "One Belt One Road”, previendo inversiones logísticas y de corredores de exportaciones en la región, tales valores incluso deben ser ampliados (CHEN, 2018; HUA et al., 2018). ${ }^{18}$

17 Cabe señalar que dos importantes empresas petroleras, las estatales Saudi Aramco y National Iranian Oil Company (NIOC), respectivamente pertenecientes a Arabia Saudita e Irán, fueron excluidas de esa lista en cuestión por el hecho de no poseer capital en los mercados accionarios y bolsas de valores. La primera hasta llegó a cogitar tal medida recientemente, sin embargo volvió atrás en la intención de apertura vía IPO (REUTERS, 2018).

18 Por cuestiones de alcance de este artículo, no podremos adentrar en todas las implicaciones de tal importante iniciativa. Para una discusión más específica sobre la misma y su correlación con el tablero energético, ver Hua et al. (2018). 
Finalmente, la última problematización planteada por Downs parecería ser corroborada a partir del momento en que el apoyo financiero del Estado chino a las NOC y sus flujos de efectivo - a través del crédito fuertemente centralizado en manos de los bancos públicos del país asiático - innegablemente les ha conferido y confiere ventajas competitivas (subsidios a riesgos) ante las grandes corporaciones privadas internacionales (TAYLOR, 2014). Sin embargo, sigue siendo extremadamente problemático medir empíricamente la amplitud de tales ganancias, no por el aporte de recursos en sí, sino por el hecho de que las firmas chinas no se comprometan directamente y con asiduidad en competición directa con las IOC. El fomento al desarrollo proporcionado a los países con los que negocia la entrada de sus empresas es un facilitador en algunas situaciones, pero no hace menos complejas tales operaciones. Beijing se utilizó de esas herramientas - en cierto sentido recurrentes en las experiencias históricas de las otras firmas petroleras en sus relaciones con los respectivos gobiernos - para expandir internacionalmente las NOC por al menos dos grandes motivos:

Una percepción generalizada tanto de la alta burocracia gubernamental china como de la burocracia del sector petrolero es que tales empresas encuentran desventajas y desequilibrios en la competencia global por reservas de recursos, en función de la inserción tardía en las negociaciones internacionales. Mientras que tales estatales iniciaron sus actividades al exterior en la década de 1990, y sólo en los años 2000 con mayor vehemencia, buena parte de las IOC ya oligopolizaban el mercado y la experiencia de la industria petrolera, operando por muchas décadas. (DOWNS, 2010);

El crecimiento de los precios mundiales del petróleo entre 2002 y 2008 amplió el poder de negociación relativo de los países poseedores de recursos, alentándolos a fortalecer el centralismo y el control estatal en estos sectores. Fue precisamente éste el caso de muchos países africanos, los cuales, desprovistos de infraestructura logística crítica y en medio de dificultades de diversificación de sus economías enfocadas en el sector primario, capitalizaron esa nueva posición proporcionada por la coyuntura para amalgamar inversiones también en otras áreas (DOWNS, 2010; TAYLOR, 2014).

En vista de estos elementos, en la subsección siguiente la discusión pasará de la estructura del mercado de petróleo a la logística de transporte de tal recurso hasta China, aclarando los principales dilemas geopolíticos y geográficos enfrentados por las autoridades del país asiático en lo que se refiere al flujo del producto hasta su destino final, así como algunas iniciativas y respuestas a los mismos. 


\section{b) El "dilema de Malaca” y los desafíos estratégicos de las rutas de transporte petrolero}

Otro obstáculo fundamental de los gobernantes chinos que debe ser aquí señalado es el desafío geográfico pertinente al "dilema de Malaca”, término inicialmente empleado por el ex presidente Hu Jintao en conferencia del PCCh, a finales de 2003, y referente al estrecho del mismo nombre situado entre la costa oriental de la isla de Sumatra, Indonesia, y la costa oeste de Malasia. Detentor de 600 millas de largo, provee el corredor y eslabón principal entre el Océano Índico y el Mar del Sur de China. Este punto geográfico asume proporciones estratégicas gigantescas tanto de orden económica como geopolítica, ya que pasan por él poco menos del $80 \%$ de las importaciones chinas de petróleo, así como buena parte del comercio con la Unión Europea, Oriente Medio y África (LANTEIGNE, 2008). En el Mapa 1 abajo es posible visualizar tal estrecho, así como las principales rutas de energía (de petróleo crudo y gas natural) que alimentan a China:

Mapa 1. Oleoductos, gasoductos y rutas marítimas de transporte de energía a China

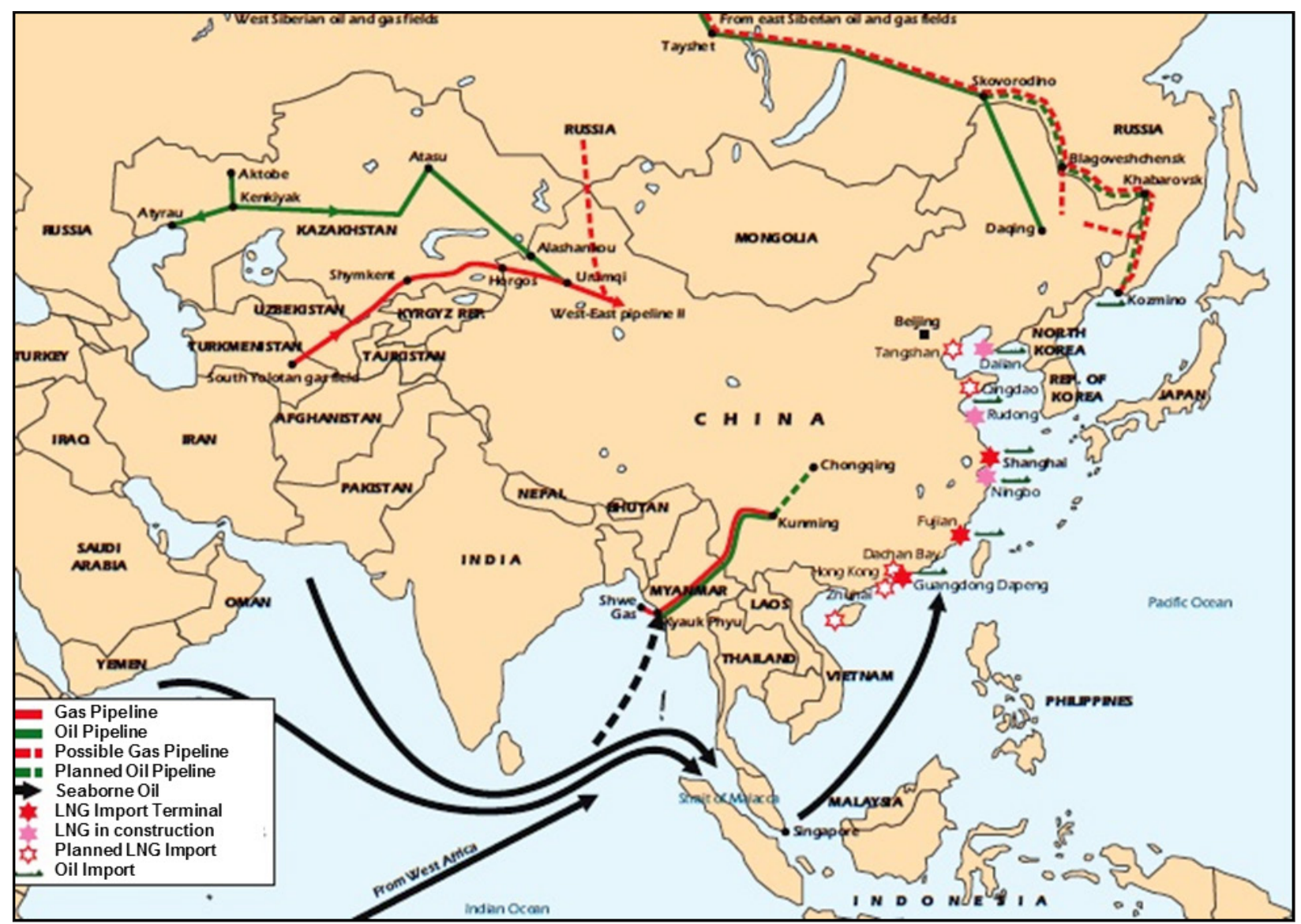

Fuente: CENTER FOR INTERNATIONAL MARITIME SECURITY, 2014. 
En función de esta importancia, los altos representantes del PCCh y del Estado chino han concentrado sus esfuerzos en mitigar la inseguridad representada por la dependencia extrema de tal punto neurálgico, que queda detrás solamente del Estrecho de Hormus en términos de volumen total de energía transportada (LANTEIGNE, 2008; CHEN, 2010; ZHAO, 2011). Sus inquietudes se dividen básicamente en dos tópicos principales:

Terrorismo marítimo (piratería), con aumento de ataques a fragatas y embarcaciones en los mares del Sudeste Asiático, principalmente a lo largo de los años 2000;19

Temores chinos en relación con la dependencia de dicho transporte en una región periférica tan conturbada, con riesgos eventuales de bloqueo en medio de rencores históricos y embrollos territoriales. Además, la presencia militar estadunidense en el Pacífico también representa un problema, en vista de las acciones ambiguas de tal potencia en intentar contemporizar la creciente influencia china. ${ }^{20}$

Para intentar solucionar este dilema estratégico, China se ancló en una actuación por diferentes vías: primero, con medidas relativas a la oferta energética, con la ya destacada diversificación de los socios comerciales de petróleo y ampliación de rutas. Segundo, a través de una estrategia militar, con adopción cautelosa de Beijing de un enfoque más constructivo junto a los propios EE.UU., para atenuar temores de los vecinos y abrir acuerdos cooperativos multilaterales de seguridad para una mayor estabilidad en los dichos mares (CHEN, 2010).

Con respecto a la diversificación de oferentes y rutas alternativas de energía, dos iniciativas en particular son de destaque imprescindible: el oleoducto y gasoducto construido conjuntamente con Myanmar y también los proyectos de explotación de la región del Ártico junto a Rusia. Esta primera iniciativa (también visible en el Mapa 1), que comenzó en octubre de 2009 y se concluyó en 2017, conectando el litoral de aquel país hasta la provincia china de Yunnan, representa un proyecto de garantía de seguridad energética en el marco de la

19 Entre 1999 y 2005, por ejemplo, se registraron 1220 ataques de piratería en el Sudeste Asiático, siendo 190 solamente en el Estrecho de Malaca (CHEN, 2010). Este índice decreció un poco a lo largo de los años subsiguientes, volviendo a aumentar a partir de 2009. De tal año hasta septiembre de 2017, ocurrieron 819 ataques en la región (INTERNATIONAL MARITIME BUREAU, 2017).

20 Con respecto a este último punto, Lanteigne (2008, p.154) subraya que representan riesgos más virtuales que reales, teniendo en cuenta que cualquier intento de interdicción de esa ruta comercial para perjudicar a China, además de ganancias cuestionables, también afectaría dramáticamente a los parceros económicos de Occidente en el Este Asiático. 
profundización de las relaciones bilaterales e integración regional (ZHAO, 2011). Con 771 kilómetros de extensión y participación mayoritaria de la CNPC (que posee el 50,9\% del capital invertido), el oleoducto guarda relevancia geopolítica extrema por conferir a la RPC acceso al Océano Índico para allá de diversificar el flujo de la commodity y proveer pasaje a más de 2 millones de toneladas de crudo al año (CHINA DAILY, 2017). ${ }^{21}$

Ya en lo que se refiere a la asociación chino-rusa en el área energética en el Ártico, la región - con recursos abundantes - ha sido objeto recientemente de tentativas diplomáticas chinas de alianzas bilaterales junto a sus naciones circundantes (ALEXEEVA; LASSERRE, 2012).22 En este sentido, fue con Rusia con quien más concentró esfuerzos y con quien encontró mayor progreso para ampliar su presencia económica y geopolítica en la región, en vista de la voluntad de Moscú de ampliar lazos de cooperación en proyectos de producción y explotación de recursos naturales. Así, ambos países pasaron a desarrollar una gama de proyectos conjuntos entre las NOC chinas y las rusas Rosneft y Gazprom, donde había sinergia en el suministro de materias primas por parte de Rusia y de fondos financieros y tecnologías por parte de los chinos (ALEXEEVA; LASSERRE, 2012; SØRENSEN; KLIMENKO, 2017).

Aunque vacilante y cauteloso, el interés chino por el Ártico sigue aumentando en la estela del desarrollo de posibilidades alternativas de flujo más allá de Malaca. Para materializar sus anhelos, China aprovechó las vulnerabilidades geoeconómicas rusas recientes (como la dependencia de las exportaciones de energía y las sanciones comerciales impuestas por las potencias occidentales tras el imbróglio ucraniano) para consolidar gradualmente su influencia en la región a través del aliado estratégico y posiblemente tener acceso en el futuro a un volumen mayor de petróleo proveniente del oleoducto conectando el Este de Siberia hasta la provincia de Heilongjiang (SØRENSEN; KLIMENKO, 2017). Esta asociación puede lanzar una nueva luz, a partir del mediano plazo, a la dependencia china del estrecho previamente mencionado, modificando tal marco.

No obstante estos proyectos e iniciativas citados, se hace acá otra observación pertinente: a pesar de la convicción de cierta parte de analistas y gobernantes chinos de que la diversificación diluiría la dependencia del Estrecho de Malaca, la idea de satisfacer la demanda energética china sólo con inversiones o flujos por

21 Zhao (2011) constituye una óptima radiografía de las relaciones entre China y Myanmar en el campo de la energía.

22 En este sentido, es imperativo denotar aquí, por ejemplo, las crecientes actividades ejercidas por CNOOC y CNPC en el norte de Canadá y en el campo de Dreki, situado entre Islandia y Noruega (SØRENSEN; KLIMENKO, 2017). 
tierra sería poco realista, demostrando una evaluación incompleta tangenciando la seguridad y las propias particularidades del mercado de petróleo (ERICKSON; COLLINS, 2011).23

Los oleoductos, por ejemplo, no son estructuralmente capaces de aumentar por sí mismos la seguridad de las importaciones chinas de petróleo: frente al crecimiento exponencial e ininterrumpido de la demanda del país asiático, mismo una posible ampliación de esos emprendimientos puede no garantizar la estabilidad de las fuentes energéticas, en función de que no tienen de la misma flexibilidad que hay en el transporte por mar. ${ }^{24}$ Por otro lado, inversiones sustanciales en iniciativas por la vía terrestre guardan efectividad y atractividad estratégica también por sus efectos de spillover, generando interdependencia y ramificaciones económicas y geográficas, apalancando relaciones comerciales y diplomáticas entre las naciones involucradas con tales proyectos. A pesar de esto, no serían solución para abordar todas las cuestiones geopolíticas inherentes al paso por Malaca, que dependerán del éxito del pragmatismo en el enfoque diplomático chino en relación con los vecinos del Sur y el Sudeste Asiático para alcanzar un consenso cooperativo, con la amalgama intrínseca y creciente entre las economías en la cadena productiva regional siendo un ingrediente favorable para su política exterior (ERICKSON; COLLINS, 2011).

Sin embargo, no se puede perder de vista que, en parte por condiciones fronterizas terrestres relativamente seguras, China hoy ve margen considerablemente mayor para operar en mar, en la medida en que prosigue con la constitución de una marina poderosa, buscando mayor influencia y ocupación en tales aguas. Es posible señalar incluso que, en el siglo XXI, la capacidad china de proyectar su hard power se dará mayoritariamente vía rutas marítimas - condiciones geográficamente más favorables (KAPLAN, 2010). A pesar de tal consideración, no se puede perder de vista el hecho de que China también enfrenta una serie de tensiones y hostilidades que van mucho más allá de Malaca, comprendiendo también puntos nodales relativos a los lechos energéticamente ricos situados en el Mar del Este de China y en el Mar del sur de China, donde Japón aparece en la disputa como un rival geopolítico.

23 También es válido resaltar que, con relación a la demanda energética, el gobierno chino (principalmente a partir de Hu Jintao y Wen Jiabao) viene actuando a través de la ampliación de las inversiones en fuentes de energía renovables, asentadas en la perspectiva a largo plazo de limpieza de la matriz y reducción de la presencia de combustibles fósiles (JIANG, 2008; CHEN, 2010).

24 Además, aunque en menor medida, oleoductos también son vulnerables a sabotajes e interdicciones militares. 
Al concluir esta parte, se vio como el perfil de la RPC, por consideraciones de propia escala y alcance de la búsqueda global por recursos, se incrementó de forma sustancial no sólo en Asia, sino en prácticamente todas partes del mundo. El punto favorable de esta asertividad sería la significativa contribución china al desarrollo de infraestructuras y capacidades productivas variadas en muchos países, principalmente naciones pobres o en desarrollo. Y por la óptica de la estrategia de seguridad, tal diplomacia pluri-direccional contribuye aún a una imagen relativamente más benéfica de la potencia asiática (FRIEDBERG, 2006). Pero, evidentemente, al paso que los demás Estados asisten al continuo aumento del consumo energético chino, sus anhelos sobre las condiciones futuras de oferta y demanda de commodities inevitablemente van a crecer, pudiendo ocasionar eventuales cambios en sus estrategias y coaliciones internacionales para actuar de forma responsiva a su ascenso económico (de China) en el futuro (CURRIER, 2012).

Sintetizando lo que fue visto en el artículo hasta ahora, la demanda por recursos naturales consolidó los eslabones de China con una gama considerable de naciones en la parte más baja de las cadenas económicas globales, principalmente las exportadoras de minerales. Tal vez la dimensión más significativa de estas relaciones sea la interconexión cada vez mayor entre esas oferentes externas con el régimen productivo chino y la incapacidad de esos países de sostener los precios globales de sus productos. Este hecho, por sí solo, puede no trasladarse directamente a una voluntad por parte de los países productores en alinear sus políticas con China, pero, sin duda, hace a sus respectivos gobiernos más atentos con sus directrices y rumbos políticos. De esta forma, la capacidad de Beijing de extraer dividendos estratégicos en el papel de consumidora (en términos de acuerdos energéticos favorables, tanto por el prisma de la diversificación como por la garantía de recursos a largo plazo) dependerá de la profundidad de la amalgama de las economías productoras junto al mercado chino. El uso político de su poder de mercado será mayor en situaciones donde China quiere firmar compromisos estratégicos a largo plazo con los potenciales ofertantes, siendo los exportadores de commodities tal vez los más prometedores en este sentido. En muchas instancias, Beijing ahora busca no meramente adquirir lo que necesita en los mercados internacionales, sino también invertir en la extracción y procesamiento, así como en ductos, rieles, carreteras y puertos. De tal manera, hace cada vez más creíble y fácil el flujo de los recursos necesarios para el país, capiéndose aún en términos de área de influencia política y económica en la periferia que se beneficia, a su vez, del desarrollo de infraestructura logística (FRIEDBERG, 2006). 


\section{Consideraciones finales}

La transición capitalista transformó a la RPC en una gigantesca consumidora e importadora de energía. Inevitablemente, catapultó la seguridad energética al tope de las consideraciones de gobierno y Estado. La supervivencia del PCCh se vincula ampliamente a la resiliencia del progreso productivo y distributivo modernizante y generador de ingresos, cada vez más dependiente de la aptitud para sostener el crecimiento económico, anclado en el acceso continuo a los recursos energéticos (WU; STOREY, 2008; ANDREWS-SPEED; DANNREUTHER, 2011).

El gobierno actuó, en el ámbito doméstico, en la gestión de tal dependencia creciente de importaciones de petróleo, buscando aumentar su conservación y eficiencia, además de perpetrar reestructuraciones en sus firmas y en el mercado interno (JIANG, 2008). Sin embargo, así como en cualquier país industrializado o en curso de industrialización, su trayectoria de desarrollo en ese sector ha traído consigo contradicciones y limitaciones, incluyendo desde la infraestructura de los recursos energéticos domésticos hasta una cierta rigidez institucional oriunda de las conturbadas relaciones entre las instancias gubernamentales definitorias de la política nacional. Este trazado traería perspectivas más escépticas sobre cualquier pronóstico de un cambio político dramático en el segmento referido, con mayor probabilidad de gradualismos (ANDREWS-SPEED; DANNREUTHER, 2011).

Los impactos de la seguridad energética en las relaciones internacionales chinas son múltiples, mostrando alta capacidad de engendrar tanto cooperación como competición con otras potencias. El objetivo central de la política exterior sigue siendo el mantenimiento de un sistema internacional, por encima de todo, estable (WU; STOREY, 2008).

El incesante requerimiento de mayores importaciones de petróleo proporcionó la lógica para la internacionalización de las NOC y la subsiguiente diplomacia de la energía, que, en términos de frutos rendidos, ha traído al largo de varios años la presencia china para más de cincuenta países, con vastos activos e inserciones en tal área - según la multiplicación de las fuentes y suministros extranjeros, la propia cuestión energética fue instrumentalizada en sintonía con iniciativas diplomáticas y viceversa (ANDREWS-SPEED; DANNREUTHER, 2011).

Se concluye, sobre la base de todos los puntos enumerados, que la profundización de las importaciones de energía fue y será un factor altamente impactante y estratégico para la integración cada vez más latente entre China y el resto del mundo. Con el objetivo de amalgamarse al sistema político y económico 
global sin desafiar directamente los intereses occidentales, los líderes de Beijing procurarán hacerlo en sus propios términos, expandiendo lazos con el mayor número de socios posibles, siendo muchos de ellos generalmente simpáticos a sus ambiciones estratégicas y a su enfoque de mayor intervencionismo estatal en el direccionamiento económico y en la propia industria petrolera.

Para allá de las relaciones comerciales amplias y su diplomacia asertiva, el expansionismo económico y militar chino en el Sur Global encuentra otro fuerte condicionante también en la demanda de energía, con los tres puntos siendo totalmente indisociables, con énfasis en América Latina, África y Oriente Medio. ${ }^{25}$ En este sentido, se concluye que su dependencia de recursos opera en doble vía: proporciona, por un lado, incentivos para el establecimiento y profundización de lazos íntimos con diversos países y continentes; y, por otro, sería también relativamente limitante de su perfil global por su peso económico crítico y por las fluctuaciones de precios (ZIEGLER, 2011).

Por último, la búsqueda de la seguridad energética por el Estado chino y el PCCh tangencia dimensiones tanto cooperativas como competitivas: la cooperación se corporifica en emprendimientos conjuntos con las IOC y en inversiones para desarrollo logístico y de infraestructura en múltiples países; y las competitivas lo son en lo que se refiere al problemático ajedrez geopolítico del petróleo, representando el gran dilema de seguridad de la RPC en sus relaciones interestatales en la periferia asiática inmediata. ${ }^{26}$

\section{Referencias}

ALEXEEVA, Olga; LASSERRE, Frédéric. The Snow Dragon: China's Strategies in the Arctic. China Perspectives, n. 2012/2013, 2012, p.61-68. Disponible en: < https://journals. openedition.org/chinaperspectives/5958 > .

ANDREWS-SPEED, Philip. Perspectives on the Governance of Energy in China. Journal of Resources and Ecology, v. 1, n. 2, 2010, p.135-144.

25 En función de que la mayor parte del petróleo disponible se encuentra en el "Sur Global”, fue lógicamente para allá que Beijing orientó sus miradas. Pero, a diferencia de lo ocurrido durante la Guerra Fría, su carrera por mayor influencia y presencia en el Tercer Mundo ya no se dirige por la inclinación ideológica, sino por intereses preponderantemente neomercantilistas y extractivistas (ZIEGLER, 2011).

26 En función, exactamente, de la continuidad de su crecimiento, reverberado por el aumento del consumo de combustibles o energético de forma general (sea civil, industrial o en el sector del transporte), continuara planteando tensiones sobre los mercados. Sólo entre 2000 y 2010, China fue responsable del 42,2\% del incremento en la demanda mundial por petróleo (PALHANO, 2012). 
ANDREWS-SPEED, Philip; DANNREUTHER, Roland. China, Oil and Global Politics. London: Routledge, 2011.

ANDREWS-SPEED, Philip; MA, Xin. The Overseas Activities of China's National Oil Companies: Rationale and Outlook. Minerals \& Energy, v. 21, n. 1, 2006, p.17-30.

BBC. Former China energy chief Jiang Jiemin jailed for corruption. 12 octubre 2015. Disponible en: < https://www.bbc.com/news/world-asia-china-34503469 > Acceso en: 5 de novembro de 2018 .

BRITISH PETROLEUM. BP Statistical Review of World Energy June 2017. Junio 2017. Disponible en: < https://www.bp.com/content/dam/bp/en/corporate/pdf/energyeconomics/statistical-review-2017/bp-statistical-review-of-world-energy-2017-fullreport.pdf > . Acceso en: 11 de janeiro de 2018 .

CABESTAN, Jean-Pierre. La Politique Internationale de la Chine. Paris: Presses de Sciences Po, 2010.

CENTER FOR INTERNATIONAL MARITIME SECURITY. Strategic Architectures. 12 Febrero 2014. Disponible en: < http://cimsec.org/strategic-architectures/9941 > Acceso en: 11 de janeiro de 2018.

CHEN, Shaofeng. Assessing the Impact of China's Foreign Energy Quest on its Energy Security. EAI Working Paper, n. 145, 2009, p.1-18.

CHEN, Shaofeng. China's Self-Extrication from the 'Malacca Dilemma' and Implications. International Journal of China Studies, v. 1, n. 1, 2010, p.1-24.

CHEN, Shaofeng. Is the Belt and Road Initiative set to enhance China's energy security?. Asia Dialogue, 19 abril. 2018. Disponible en: < http://theasiadialogue.com/2018/04/19/ is-the-belt-and-road-initiative-set-to-enhance-chinas-energy-security/ > . Acceso en: 6 de novembro de 2018.

CHINA DAILY. Oil starts flowing through China-Myanmar pipeline. 12 abril 2017. Disponible en: < http://www.chinadaily.com.cn/business/2017-04/12/content_28886175.htm > . Acceso en: 7 de novembro de 2018.

CURRIER, Carrie Liu. China and the Global Surge for Resources. In KAVALSKY, Emilian (Ed.). The Ashgate Research Companion to Chinese Foreign Policy. Surrey: Ashgate, 2012. Cap. 12, p.163-175.

DOWNS, Erica. Who's Afraid of China’s Oil Companies?. In PASCUAL, Carlos; ELKIND, Jonathan. (eds.). Energy Security: Economics, Politics, Strategy and Implications. Washington: Brookings Institution Press, 2010. Cap. 4, p.73-102.

ERICKSON, Andrew; COLLINS, Gabriel. Pipelines versus Sea Lanes: Challenges and Opportunities for Securing Energy Resources. In.: CURRIER, Carrie Liu; DORRAJ, Manochehr (eds.). China's Energy Relations with the Developing World. London: Continuum, 2011. Cap. 9, p.175-194. 
FORBES. The World's 25 Biggest Oil Companies. 2017a. Disponible en: < https://www. forbes.com/pictures/mef45glfe/not-just-the-usual-suspects-2/\#5cdd98d03ef5 > . Acceso en: 13 de janeiro de 2018.

FORBES. The World's Biggest Public Companies. 2017b. Disponible en: < https://www. forbes.com/global2000/list/\#tab:overall > . Acceso en: 13 de janeiro de 2018.

FRIEDBERG, Aaron. Going Out: China's Pursuit of Natural Resources and Implications for the PRC's Grand Strategy. NBR Analysis, v. 17, n. 3, 2006, p.5-34.

GARRISON, Jean. The Domestic Political Context for China's Quest for Energy Security. In CURRIER, Carrie Liu; DORRAJ, Manochehr (Eds.). China's Energy Relations with the Developing World. London: Continuum, 2011. Cap. 3, p.38-62.

GOLDSTEIN, Avery. The Diplomatic Face of China's Grand Strategy: A Rising Power's Emerging Choice. The China Quarterly, n.168, 2001, p.835-864.

HEBRON, Lui. The Evolution of China's Grand Strategy with the Developing World. In CURRIER, Carrie Liu; DORRAJ, Manochehr (eds.). China's Energy Relations with the Developing World. London: Continuum, 2011. Cap. 2, p.17-37.

HUA, Yinxiao et al. Oil, Gas and Energy Business under One Belt One Road Strategic Context. Open Journal of Social Sciences, n. 6, 2018, p.119-134.

INTERNATIONAL ENERGY AGENCY. Key World Energy Statistics. 2017. Disponible en: < https://www.iea.org/publications/freepublications/publication/KeyWorld2017. pdf > . Acceso en: 11 de janeiro de 2018.

INTERNATIONAL MARITIME BUREAU. Piracy and Armed Robbery Against Ships. 2017. Disponible en: < http://www.hellenicshippingnews.com/wp-content/ uploads/2017/10/2017-Q3-IMB-Piracy-Report-Abridged.pdf > . Acceso en: 13 de janeiro de 2018.

JIANG, Zemin. Reflections on Energy Issues in China. Journal of Shanghai Jiaotong University, v. 13, n. 3, 2008, p.257-274.

JIANG, Julie; SINTON, Jonathan. Overseas Investments by Chinese National Oil Companies: Assessing the drivers and impacts. IEA Information Paper, 2011, p.1-48.

KAMBARA, Tatsu; HOWE, Christopher. China and the Global Energy Crisis: Development and Prospects for China's Oil and Natural Gas. Cheltenham: Edward Elgar, 2007.

KAPLAN, Robert. The Geography of Chinese Power: How Far Can Beijing Reach on Land and Sea?. Foreign Affairs, v. 83, n. 3, 2010, p.22-41.

KLARE, Michael. No Blood for Oil? Hydrocarbon Abundance and International Security. In KLARE, Michael et al. (eds.). The Palgrave Handbook of the International Political Economy of Energy. Basingstoke: Palgrave Macmillan, 2016. Cap. 17, p.419-440.

LAI, Hongyi; KANG, Su-Jeong. Economic Development and China's Foreign Policy. In KAVALSKY, Emilian (ed.). The Ashgate Research Companion to Chinese Foreign Policy. Surrey: Ashgate, 2012. Cap. 8, p.113-121. 
LANTEIGNE, Marc. China's Maritime Security and the 'Mallacca Dilemma. Asian Security, Vol. 4, N. 2, 2008.

LI, Mingjiang. International Status: China's Pursuit of a Comprehensive Superpower Status. In KAVALSKY, Emilian (ed.). The Ashgate Research Companion to Chinese Foreign Policy. Surrey: Ashgate, 2012. Cap. 2, p.33-45.

MEIDAN, Michael. The structure of China's oil industry: Past trends and future prospects. The Oxford Institute of Energy Studies (OIES) Paper, n. 66, 2016, p.1-58. Disponible en: < https://www.oxfordenergy.org/wpcms/wp-content/uploads/2016/05/Thestructure-of-Chinas-oil-industry-past-trends-and-future-prospects-WPM-66.pdf > .

NATIONAL BUREAU OF STATISTICS. China Energy Statistical Yearbook. Beijing: China Statistics Press, 2017.

NAUGHTON, Barry. Growing Out of the Plan: Chinese Economic Reform, 1978-1993. Cambridge: Cambridge University Press, 1995.

NAUGHTON, Barry. The Chinese Economy: Transitions and Growth. Cambridge, Massachusetts: the MIT Press, 2007.

NOLAN, Peter. China and the Global Economy: National Champions, Industrial Policy, and the Big Business Revolution. London: Palgrave Macmillan, 2001.

NOLAN, Peter. Re-Balancing China: Essays on the Global Financial Crisis, Industrial Policy and External Relations. London: Anthem Press, 2013.

NUNES, Carlos Costa. O Conceito de Segurança Energética. População e Prospectiva Working Papers, n. 17, 2013, p.1-63. Disponible en: < http://www.cepese.pt/portal/ pt/publicacoes/colecoes/working-papers/populacao-e-prospectiva/o-conceito-deseguranca-energetica/O \% 20Conceito \% 20de \% 20Seguranca \% 20Energetica.pdf > .

PALHANO, Alexandre. Segurança Energética da China, um estudo das relações entre Estado e Mercado com foco na indústria de petróleo e gás natural no período de 1978 a 2010. Tesis (Doctorado en Ciencias Económicas), Universidad Federal del Rio de Janeiro, Rio de Janeiro, 2012.

PEOPLE'S REPUBLIC OF CHINA. China Going Global: between ambition and capacity. 2017. Disponible en: < https://policycn.com/wp-content/uploads/2017/05/2017Chinas-going-global-strategy.pdf > . Acceso en: 6 de noviembre de 2018.

PINTO, Eduardo Costa. O eixo sino-americano e as transformações do sistema mundial: tensões e complementaridades comerciais, produtivas e financeiras. In PINTO, Eduardo Costa; LEÃO, Rodrigo Pimentel Ferreira; ACIOLY, Luciana (orgs.). A China na Nova Configuração Global: impactos políticos e econômicos. Brasília: IPEA, 2011. Cap.1, p. 19-78.

REUTERS. Inside Xi Jinping's purge of China's oil mandarins. 24 julio 2014. Disponible en: < https://www.reuters.com/article/us-china-purge-cnpc-specialreport/insidexi-jinpings-purge-of-chinas-oil-mandarins-idUSKBNOFT2NK20140724 > . Acceso en: 5 de noviembre de 2018 . 
REUTERS. Exclusive: Aramco IPO halted, oil giant disbands advisers - source. 22 agosto 2018. Disponible en: < https://www.reuters.com/article/us-saudi-aramco-ipo-exclusive/ exclusive-aramco-ipo-halted-oil-giant-disbands-advisers-sources-idUSKCN1L71TZ > . Acceso en: 2 de noviembre de 2018.

SHAMBAUGH, David. China Goes Global: The Partial Power. Oxford: Oxford University Press, 2013.

SHI, Yinhong. The impact of China's capitalist transition on foreign policy. In MCNALLY, Christopher (ed.) China's emergent political economy: capitalism in the dragon's lair. London: Routledge, 2008. Cap. 11, p. 209-227.

SØRENSEN, Camilla; KLIMENKO, Ekaterina. Emerging Chinese-Russian Cooperation in the Arctic: Possibilities and constraints. SIPRI Policy Paper, n. 46, 2017. p. 1-43. SUTTER, Robert. Chinese Foreign Relations: Power and Policy since the Cold War. $3^{\mathrm{a}}$ ed. New York: Rowman \& Littlefield Publishers Inc, 2012.

TAYLOR, Monique. The Chinese State, Oil and Energy Security. Basingstoke: Palgrave Macmillan, 2014.

UNITED STATES ENERGY INFORMATION ADMINISTRATION. China Overview. 14 mayo 2015. Disponible en: < https://www.eia.gov/beta/international/analysis.cfm?iso = CHN > . Acceso en: 11 de enero de 2018.

UNITED STATES ENERGY INFORMATION ADMINISTRATION. International Energy Statistics. 2017. Disponible en: < https://www.eia.gov/beta/international/data/br owser $/ \# /$ ?pa $=0000001 \& \mathrm{c}=$ ruvvvvvfvtvnvv1 urvvvvfvvvvvvfvvvou20evvvvvvvvvn vvuvo\&ct $=0 \&$ tl_id $=5$-A\&vs $=$ INTL.5-2-CHN-TBPD.A\&ord $=$ CR\&cy $=2015 \& v o=0 \& v$ $=$ H\&end $=2016>$. Acceso en: 11 de enero de 2018.

WU, Kang; STOREY, Ian. Energy security in China's capitalist transition. In MCNALLY, Christopher (ed.). China's emergent political economy: capitalism in the dragon's lair. London: Routledge, 2008. Cap. 10, p. 190-208.

YERGIN, Daniel. Ensuring Energy Security. Foreign Affairs, 2006. Disponible en: https://www.foreignaffairs.com/articles/2006-03-01/ensuring-energy-security. Acceso en: 2 de noviembre de 2018.

YERGIN, Daniel. The Quest: Energy, Security, and the Remaking of the Modern World. New York: The Penguin Press, 2011.

ZHANG, Baijia. The Path of the CPC: Revolution, Construction and Reform. Beijing: Foreign Languages Press, 2012.

ZHAO, Hong. China-Myanmar Energy Cooperation and Its Regional Implications. Journal of Current Southeast Asian Affairs, v. 30, n.4, 2011. p.89-109.

ZIEGLER, Charles. China's Energy Relations with the Global South: Potential for Great Power Realignment. In CURRIER, Carrie Liu; DORRAJ, Manochehr (eds.). China's Energy Relations with the Developing World. London: Continuum, 2011. Cap. 10, p. 195-212. 